\title{
Plasma cytokine concentrations in workers exposed to 2,3,7,8-tetrachlorodibenzo-p-dioxin (TCDD)
}

\author{
Fatemeh Saberi Hosnijeh ${ }^{1,2}$, Daisy Boers ${ }^{1}$, Lützen Portengen ${ }^{1}$, H. Bas Bueno-de-Mesquita ${ }^{3,4}$, Dick Heederik $^{1}$ \\ and Roel Vermeulen ${ }^{1,5}$ *
}

${ }^{1}$ Division Environmental Epidemiology, Institute for Risk Assessment Sciences, Utrecht University, Utrecht, Netherlands

2 Zanjan University of Medical Science, Zanjan, Iran

${ }^{3}$ National Institute for Public Health and Environment, Bilthoven, Netherlands

${ }^{4}$ Department of Gastroenterology and Hepatology, University Medical Centre, Utrecht, Netherlands

${ }_{5}^{5}$ Julius Center for Health Sciences and Primary Care, University Medical Center Utrecht, Utrecht, Netherlands

Edited by:

Min Dai, Chinese Academy of

Medical Sciences, China

\section{Reviewed by:}

Maria Paula Curado, International

Prevention Research Institute, France

Ning Lu, University of Texas MD

Anderson Cancer Center, USA

\section{*Correspondence:}

Roel Vermeulen, Division

Environmental Epidemiology, Institute

for Risk Assessment Sciences,

Jenalaan 18D, PO Box 80178, 3508

TD Utrecht, Netherlands.

e-mail: r.c.h.vermeulen@uu.nl

\begin{abstract}
Objectives: Few epidemiological studies have studied the effect of 2,3,7,8tetrachlorodibenzo-p-dioxin (TCDD) on blood cytokine levels. In this study we investigated changes in plasma levels of a large panel of cytokines, chemokines, and growth factors among workers from a Dutch historical cohort occupationally exposed to chlorophenoxy herbicides and contaminants including TCDD. Methods: Eighty-five workers who had been exposed to either high $(n=47)$ or low $(n=38)$ TCDD levels more than 30 years before serum collection were included in the current investigation. Plasma level of 16 cytokines, 10 chemokines, and 6 growth factors were measured. Current plasma levels of TCDD (TCDD $\left.{ }_{\text {current }}\right)$ were determined by high-resolution gas chromatography/isotope-dilution high-resolution mass spectrometry. TCDD blood levels at the time of last exposure $\left(T C D D_{\max }\right)$ were estimated using a one-compartment first order kinetic model. Results: Blood levels of most analytes had a negative association with current and estimated past maximum TCDD levels. These decreases reached formal statistical significance for fractalkine, transforming growth factor alpha (TGF- $\alpha$ ), and fibroblast growth factor 2 (FGF2) with increasing TCDD levels. Conclusion: Our study showed a general reduction in most analyte levels with the strongest effects for fractalkine, FGF2, and TGF- $\alpha$. These findings suggest that TCDD exposure could suppress the immune system and that chemokine and growth factor-dependent cellular pathway changes by TCDD may play role in TCDD toxicity and associated health effects.
\end{abstract}

Keywords: dioxin, cytokine, chemokine, growth factor, NHL

\section{INTRODUCTION}

Immune suppression by 2,3,7,8-tetrachlorodibenzo-p-dioxin (TCDD) has been established in animal and experimental studies (Marshall and Kerkvliet, 2010; Zhang et al., 2010). These studies showed that TCDD produces a wide range of toxic effects on all components of the immune system including cytokines and chemokines and might cause imbalance between T helperl and T helper2 cytokines (Fujimaki et al., 2002; Ito et al., 2002; Nohara et al., 2002; Boverhof et al., 2004). However, few epidemiological studies have evaluated TCDD effects on cytokine levels in humans. These studies showed that TCDD exposure could reduce serum IL4 levels (Oh et al., 2005) and INF- $\gamma$ (Kim et al., 2003; Oh et al., 2005) and/or increase IL4 and IL10 levels (Kim et al., 2003). Another study found no changes in measured cytokine levels (Neubert et al., 2000).

Exposure to chlorophenoxy herbicides or chlorophenols has been shown to be associated with non-Hodgkin lymphoma (NHL), in particular with TCDD exposure (Kogevinas et al., 1997; Hardell et al., 1998; Bertazzi et al., 2001; Bodner et al., 2003; Consonni et al., 2008). As the immune system has a possible role in the development of lymphomas in particular
NHL (Dean et al., 1999; Pillemer, 2006; Rothman et al., 2006; Dave, 2010; Gascoyne and Steidl, 2011; Purdue et al., 2011), the possible link between NHL and TCDD might be governed by TCDD-related perturbations (i.e., suppression) of the immune system.

Cytokines play a pivotal role in immune function. Therefore, blood levels of multiple cytokines collectively might appropriately reflect subtle status of a deregulated immune response or a failure to modulate the immune response due to TCDD exposure. Previous studies investigating the effects of TCDD exposure on blood cytokine levels only studied a few selected cytokines and results showed considerable discrepancies. Here, we set out to investigate the association between exposure to TCDD and plasma concentration of a large panel of cytokines, chemokines, and growth factors in subjects historically exposed to TCDD. Study subjects comprised a subset of a retrospective cohort of Dutch workers, part of the IARC multinational study of workers exposed to chlorophenoxy herbicides, chlorophenols, and dioxins during their working life (Bueno de Mesquita et al., 1993; Kogevinas et al., 1997; Hooiveld et al., 1998; Boers et al., 2010; Saberi Hosnijeh et al., 2011). 


\section{MATERIALS AND METHODS STUDY POPULATION}

The cohort study design and exposure assessment have been previously described in detail (Bueno de Mesquita et al., 1993; Hooiveld et al., 1998; Boers et al., 2010). Briefly, the cohort consists of workers from two chlorophenoxy herbicide producing factories. Current analyses utilized a subset of workers from one factory (labeled "A" in previous publications) who were exposed to TCDD as a byproduct of the production of 2,4,5-trichlorophenoxyacetic acid and 2,4,5-trichlorophenol during 1953-1969, and/or during an uncontrolled reaction in 1963. High-exposed workers were selected for blood collection if (1) they were still alive at the end of follow-up (December 31st, 2006); (2) they had been exposed due to the industrial accident (both factory workers and contract workers hired to clean-up after the accident; $n=29)$; or if (3) they worked in departments of main production $(n=21)$. High-exposed workers were matched to 43 low-exposed workers employed in non-production departments by factory, sex, age (within 5 years), and current residence (at first two digits of postal code). All study subjects were male. The study was conducted with the approval of the Medical Ethics Committee of the University Medical Center Utrecht, the Netherlands and written informed consent was obtained from each study subject after the study was explained. Participants were asked to complete a self-administered questionnaire, which included questions on occupational history, personal medical history, medication used in the weeks before the study, anthropometric characteristics, smoking status, and alcohol intake. Blood plasma samples were collected according to a standard protocol during home visits between May 2007 and September 2008 (Boers et al., 2012; Saberi Hosnijeh et al., 2011).

\section{CYTOKINES MEASUREMENTS}

Blood samples were generally collected in the afternoon, but occasionally also early morning or in the evening. Samples were processed within $1 \mathrm{~h}$ of being collected and stored on ice at $0^{\circ} \mathrm{C}$, and were transported to the lab where they subsequently were stored at $-80^{\circ} \mathrm{C}$. Heparinized plasma samples were analyzed for a large panel of cytokines, chemokines, and growth factors including interleukin (IL) $1 \beta$, IL2, IL4, IL5, IL6, IL7, IL8, IL10, IL12, IL13, interferon alpha (INF- $\alpha$ ), interferon gamma (INF- $\gamma$ ), tumor necrosis factor alpha (TNF- $\alpha$ ), eotaxin, IL1 receptor antagonist (IL1ra), interferon gamma-induced protein 10 (IP10), granulocyte-macrophage colony-stimulating factor (GMCSF), epidermal growth factor (EGF), fibroblast growth factor 2 (FGF2), fms-like tyrosine kinase receptor-3 (Flt3) ligand protein (Flt3 ligand), granulocyte colony-stimulating factor (GCSF), melanoma growth stimulatory activity/growth-related oncogene (GRO), monocyte chemotactic protein-1 (MCP-1), monocyte chemotactic protein-3 (MCP-3), macrophage derived chemokine (MDC), macrophage inflammatory protein-1 alpha (MIP-1 $\alpha$ ), macrophage inflammatory protein-1 beta (MIP-1 $\beta$ ), soluble CD40 ligand (sCD40L), soluble IL2 receptor alpha (sIL2R $\alpha)$, transforming growth factor alpha (TGF- $\alpha$ ), and vascular endothelial growth factor (VEGF) using the milliplex HCYTOMAG-60SK and HSCYTMAG-60SK kits, according to the protocol described by the manufacturer. Blood samples of high and low-exposed workers were randomly analyzed on two plates. A subset of samples
(15 high-exposed and 14 low-exposed) were analyzed in duplicate. The median coefficient of variation for all analytes measured in duplicate was $11.9 \%(0.69-79.8)$. Intra class of correlation coefficients (ICCs) varied from 0.31 to 0.98 with a median of 0.72 . The lower limits of detection (LOD) were $0.04 \mathrm{pg} / \mathrm{mL}$ for IL5, $0.05 \mathrm{pg} / \mathrm{mL}$ for IL8, $0.06 \mathrm{pg} / \mathrm{mL}$ for IL $1 \beta, 0.07 \mathrm{pg} / \mathrm{mL}$ for TNF- $\alpha, 0.15 \mathrm{pg} / \mathrm{mL}$ for GMCSF, $0.18 \mathrm{pg} / \mathrm{mL}$ for IL13 and INF$\gamma, 0.20 \mathrm{pg} / \mathrm{mL}$ for IL6 and IL7, $0.26 \mathrm{pg} / \mathrm{mL}$ for IL2, $0.34 \mathrm{pg} / \mathrm{mL}$ for IL12, $0.42 \mathrm{pg} / \mathrm{mL}$ for IL4, $0.48 \mathrm{pg} / \mathrm{mL}$ for IL10, $0.8 \mathrm{pg} / \mathrm{mL}$ for TGF- $\alpha, 1.8 \mathrm{pg} / \mathrm{mL}$ for GCSF, $1.9 \mathrm{pg} / \mathrm{mL}$ for MCP-1, $2.8 \mathrm{pg} / \mathrm{mL}$ for EGF, $2.9 \mathrm{pg} / \mathrm{mL}$ for MIP- $1 \mathrm{a}$ and INF- $\alpha, 3.0 \mathrm{pg} / \mathrm{mL}$ for MIP-1b, $3.6 \mathrm{pg} / \mathrm{mL}$ for $\mathrm{MDC}, 3.8 \mathrm{pg} / \mathrm{mL}$ for MCP-3, $4.0 \mathrm{pg} / \mathrm{mL}$ for eotaxin, $5.1 \mathrm{pg} / \mathrm{mL}$ for $\mathrm{sCD} 40 \mathrm{~L}, 5.4 \mathrm{pg} / \mathrm{mL}$ for Flt3 ligand, $7.6 \mathrm{pg} / \mathrm{mL}$ for FGF2, $8.3 \mathrm{pg} / \mathrm{mL}$ for IL1 ra, $8.6 \mathrm{pg} / \mathrm{mL}$ for IP10, $9.9 \mathrm{pg} / \mathrm{mL}$ for GRO, $11.2 \mathrm{pg} / \mathrm{mL}$ for sIL2Ra, $22.7 \mathrm{pg} / \mathrm{mL}$ for fractalkine, $26.3 \mathrm{pg} / \mathrm{mL}$ for VEGF.

\section{EXPOSURE MEASUREMENTS}

Heparin plasma samples of all subjects were analyzed for TCDD, at the Centers for Diseases Control and Prevention (CDC; Atlanta, USA) using high-resolution gas chromatography/isotope-dilution high-resolution mass spectrometry. Results were lipid adjusted and reported as parts per trillion (ppt) (Patterson et al., 1991).

\section{EXPOSURE METRICS}

TCDD is highly persistent with a long half-life in blood and human tissues. As we measured current levels of TCDD $\left(\mathrm{TCDD}_{\text {current }}\right)$ approximately 35 years since last occupational exposure, a onecompartment first order kinetic model with a TCDD half-life $\left(t_{1 / 2}\right)$ of 7.1 years was used to estimate TCDD blood levels at the time of last occupational exposure (TCDD $\max$ ) (Boers et al., 2010, 2012; Saberi Hosnijeh et al., 2011):

$$
\begin{aligned}
\mathrm{TCDD}_{\max }= & \text { backround }+(\text { measured TCDD }- \text { background })^{*} \\
& \exp \left(\ln (2)^{*} \operatorname{tag} / t_{1 / 2}\right)
\end{aligned}
$$

Current TCDD levels and estimated maximum TCDD levels were subsequently used to investigate exposure-response relations between TCDD levels and analytes measured.

\section{STATISTICAL ANALYSIS}

Individual TCDD levels and analyte concentrations which were below the LOD were imputed via a maximum likelihood estimation method (Lubin et al., 2004). This procedure generates unbiased statistics when at least $50 \%$ of measurements are above the limit of detection (Lubin et al., 2004). Therefore, no summary statistics were calculated for cytokines with more than $50 \%$ of measures below the LOD (IL1 $\beta$, IL2, IL12, IL13, INF- $\gamma$, Flt3 ligand, INF- $\alpha$, IL1ra, MCP-3, sIL2Ra, and VEGF). TCDD levels and analytes concentrations were natural $\log (\ln )$-transformed as measured levels appeared to follow a log-normal distribution. Differences in continuous and categorical parameters between exposed and low-exposed subjects were tested using a two sample $t$-test and chi-square test, respectively.

We modeled exposure-response relations between lntransformed analyte concentrations as the dependent variable and ln-transformed TCDD ${ }_{\text {current }}$ or TCDD $\mathrm{T}_{\max }$ as the independent 
variable using linear regression analyses. Models were adjusted for potential confounders including body mass index (in $\mathrm{kg} / \mathrm{m}^{2}$; continuous variable); alcohol intake (unit/week; continuous variable), smoking (categorical variable; current, former, never), medication (yes/no; immunosuppressant, antibiotics, anti-inflammatory drugs), and chronic and acute medical conditions (present/absent) and laboratory testing day/batch (day 1,2 ). As more than $50 \%$ of high and low-exposed workers had a chronic disease, exposureresponse relations were also investigated in subjects free of chronic disease as a sensitivity analysis. A second sensitivity analyses was performed among workers who did not use any immunosuppressant drugs. Finally, we corrected the associations for blood cell counts (major cell types including white blood cells, lymphocytes, B cells, and monocytes; Saberi Hosnijeh et al., submitted) in order to remove the possibility that effects in analyte concentrations were driven by a reduction in absolute cell counts.

Statistical analyses were performed using SAS (ver. 9.2; SAS Institute Inc., Cary, NC, USA). All $p$-values were two-sided, with $p<0.05$ considered statistically significant.

\section{RESULTS \\ CHARACTERISTICS OF PARTICIPANTS}

Two subjects with missing TCDD results as well as six subjects with a previous cancer (non-skin) diagnosis (two high-exposed and four low-exposed workers) were removed from the analyses. The latter exclusion was made to remove the possibility that analytes levels may have been changed in subjects due to malignant disease or treatment. Therefore, a total of 85 subjects ( 47 highexposed workers and 38 low-exposed workers) were available for analysis. Exclusion of study subjects did not result in a distortion of the frequency matching status. Plasma cytokines, chemokines, and growth factors concentrations were successfully measured in all workers.

Subject characteristics $(n=85)$ are shown in Table 1. Lowexposed workers had higher alcohol intake compared to highexposed workers $(p=0.05)$. Smoking status among high and lowexposed workers was similar. Although the distribution of chronic diseases, chronic inflammatory diseases, and infection were similar among high and low-exposed workers, more than $50 \%$ of high and low-exposed workers suffered from chronic diseases such as diabetes, cardiovascular diseases, and hypertension. Geometric mean (GM) and geometric SD (GSD) levels of TCDD current and historical maximum exposure $\left(\mathrm{TCDD}_{\max }\right)$ were significantly higher in high-exposed workers $\left(\mathrm{TCDD}_{\text {current }}\right.$ : $3.25 \pm 7.43 \mathrm{ppt}$; $\left.\mathrm{TCDD}_{\max }: 79.82 \pm 33.28 \mathrm{ppt}\right)$ compared to low-exposed workers $\left(\mathrm{TCDD}_{\text {current }}: 1.07 \pm 6.42 \mathrm{ppt}\right.$; $\left.\mathrm{TCDD}_{\max }: 7.53 \pm 32.14 \mathrm{ppt}\right)$. However, TCDD exposure levels between high- and low-exposed workers largely overlapped (data not shown).

\section{CYTOKINE CONCENTRATIONS}

Table 2 shows cytokine, chemokine, and growth factor levels for high and low-exposed workers. Blood levels of most analytes were lower in high-exposed workers as compared to low-exposed workers. This reduction varied from $1 \%$ for MDC to $67 \%$ for GMCSF

Table 1 | General characteristics of high and low TCDD exposed workers.

\begin{tabular}{|c|c|c|c|}
\hline & High-exposed ( $n=47)$ & Low-exposed $(n=38)$ & $p$-Value ${ }^{f}$ \\
\hline Age (years)* & $69.07(7.45)$ & $68.55(7.93)$ & 0.75 \\
\hline Body mass index $\left(\mathrm{kg} / \mathrm{m}^{2}\right)^{*}$ & $27.33(3.10)$ & $26.65(3.04)$ & 0.31 \\
\hline Alcohol intake (units/week)* & $11.48(13.56)$ & $17.26(13.16)$ & 0.05 \\
\hline Smoking status, $N(\%)$ & & & 0.84 \\
\hline Current smoker & $12(25.5)$ & $8(21.1)$ & \\
\hline Former smoker & $28(59.6)$ & $23(60.5)$ & \\
\hline Never smoker & $7(14.9)$ & $7(18.4)$ & \\
\hline Skin cancer, $N(\%)$ & $4(8.5)$ & $3(7.9)$ & 0.92 \\
\hline Infectious disease in the past 4 weeks, $N(\%)$ & $4(8.7)$ & $4(10.5)$ & 0.78 \\
\hline Chronic disease, $N(\%)^{\dagger}$ & $24(51.1)$ & $20(52.6)$ & 0.89 \\
\hline Chronic inflammatory disease, $N(\%)^{\ddagger}$ & $13(27.7)$ & $11(28.9)$ & 0.90 \\
\hline Medication, $N(\%)$ & & & 0.33 \\
\hline Immunosuppressant & $5(10.6)$ & $4(10.5)$ & \\
\hline NSAIDs & $14(29.8)$ & $6(15.8)$ & \\
\hline Antibiotics & 0 & $1(2.6)$ & \\
\hline $\mathrm{TCDD}_{\text {current }}(\mathrm{ppt})^{\mathrm{a}}$ & $3.25(7.43)$ & $1.07(6.42)$ & 0.002 \\
\hline $\mathrm{TCDD}_{\max }(p p t)^{\mathrm{b}}$ & $79.82(33.28)$ & $7.53(32.14)$ & 0.001 \\
\hline
\end{tabular}

*Mean (SD); NSAIDs, non-steroidal anti-inflammatory drugs.

${ }^{\dagger}$ Chronic diseases included: diabetes, coronary heart disease, and hypertension.

${ }^{\ddagger}$ Chronic inflammatory diseases: chronic obstructive pulmonary disease, psoriasis, sarcoidosis, asthmatic bronchitis, rheumatoid arthritis, liver failure, Crohn's disease, fibromyalgia, and allergy.

${ }^{a}$ Current levels of 2,3,7,8-tetrachlorodibenzo-p-dioxin (TCDD ${ }_{\text {current }}$ ) parts per trillion, geometric mean (geometric SD).

${ }^{b}$ Estimated maximum levels of TCDD (TCDD ${ }_{\max }$ ) parts per trillion, geometric mean (geometric SD).

${ }^{\mathrm{E}} \mathrm{p}$-values from $t$-tests for continuous variables and $\chi^{2}$ tests for categorical variables. 
Table 2 | Plasma cytokines concentrations among high and low TCDD exposed workers $(n=85)$.

\begin{tabular}{|c|c|c|c|c|c|c|}
\hline & \multirow[t]{2}{*}{ Out of $114^{\mathrm{a}}$ measurement, $n<$ LOD } & \multicolumn{2}{|c|}{ High-exposed $(n=47)$} & \multicolumn{2}{|c|}{ Low-exposed $(n=38)$} & \multirow[t]{2}{*}{$p$-Value* } \\
\hline & & GM & GSD & GM & GSD & \\
\hline IL5 & 21 & 0.19 & 5.21 & 0.37 & 3.78 & 0.05 \\
\hline IL6 & 6 & 2.38 & 3.19 & 3.13 & 4.66 & 0.35 \\
\hline IL7 & 17 & 0.41 & 2.61 & 0.58 & 3.94 & 0.16 \\
\hline IL10 & 9 & 4.39 & 3.86 & 4.35 & 3.78 & 0.97 \\
\hline GMCSF & 24 & 0.32 & 8.08 & 0.97 & 11.47 & 0.03 \\
\hline TNF- $\alpha$ & 2 & 5.37 & 2.61 & 5.70 & 2.44 & 0.77 \\
\hline EGF & 19 & 16.12 & 5.37 & 25.53 & 6.05 & 0.24 \\
\hline Eotaxin & 1 & 340.36 & 2.53 & 395.44 & 2.16 & 0.41 \\
\hline FGF2 & 47 & 8.1 & 4.69 & 8.67 & 6.23 & 0.88 \\
\hline IP10 & 4 & 445.86 & 3.29 & 411.58 & 2.92 & 0.75 \\
\hline MCP-1 & 3 & 262.43 & 3.78 & 239.85 & 4.39 & 0.77 \\
\hline MDC & 0 & 772.78 & 1.68 & 780.55 & 1.80 & 0.95 \\
\hline $\mathrm{MIP}-1 \alpha$ & 43 & 2.72 & 4.39 & 0.38 & 4.95 & 0.91 \\
\hline MIP-1b & 19 & 14.73 & 4.53 & 20.91 & 4.44 & 0.28 \\
\hline sCD40L & 2 & 854.06 & 3.82 & 1312.91 & 2.64 & 0.10 \\
\hline TGF- $\alpha$ & 29 & 0.65 & 4.57 & 1.04 & 5.75 & 0.19 \\
\hline
\end{tabular}

GM, geometric mean; GSD, geometric SD; IL, interleukin; GMCSF, granulocyte-macrophage colony-stimulating factor; TNF-a, tumor necrosis factor alpha; EGF,

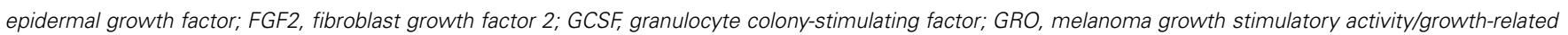

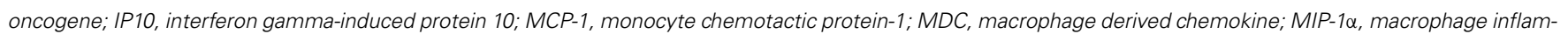

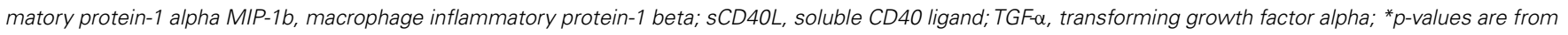
t-tests of natural log-transformed values; ${ }^{a}$ all measurements including duplicates.

$($ mean $=28.5 \%)$. A significant decrease in IL5 and GMCSF levels was found among high and low-exposed workers.

\section{DOSE-RESPONSE ANALYSES}

Linear regression analysis showed that most of measured analytes had a negative, although non-significant, association with

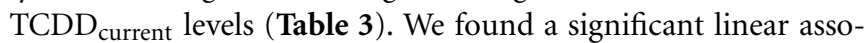

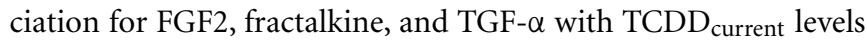
in both univariate and multivariate analyses. Sensitivity analysis restricted to chronic disease-free subjects and to subjects using no immunosuppressant drugs showed similar results except that TGF- $\alpha$ and FGF2 became non-significant because of limited power (data not shown). When we corrected observed multivariate associations for major blood cell counts (Saberi Hosnijeh et al., submitted), fractalkine, and TGF- $\alpha$ remained significantly associated. Subsequently, regression analyses were done for high and lowexposed subjects separately. Although these analyses showed negative trends for fractalkine, FGF2, and TGF- $\alpha$ with current TCDD levels among both high and low-exposed workers (Figure 1), the associations were statistically significant only among high-exposed workers. Regression analyses with estimated maximum TCDD levels at time of last exposure $\left(\mathrm{TCDD}_{\max }\right)$ rendered essentially similar results albeit associations were slightly weaker (data not shown).

\section{DISCUSSIONS}

The present paper reports on associations between past occupational exposure to high levels of TCDD and plasma levels of several cytokines, chemokines, and growth factors in a peripheral blood sample of workers exposed to the high levels of TCDD approximately 35 years prior to blood collection. We found a nonsignificant reduction in plasma levels of most measured analytes with increasing levels of TCDD. However only fractalkine, TGF- $\alpha$, and FGF2 showed a statistically significant association with TCDD levels. Our study is the first study to evaluate plasma levels of a large panel of cytokines in relation to TCDD exposure in humans.

Our results showed an overall decrease in plasma levels of most cytokines, chemokines, and growth factors with increasing TCDD levels. There is limited evidence in the literature on plasma levels of cytokines in relation to TCDD exposure, probably because populations exposed exclusively or primarily to TCDD are rare. Oh et al. (2005) measured serum IL4 and INF- $\gamma$ among waste incineration workers and showed a reduction in both cytokines in the exposed workers $(n=31)$ compared to the matched, unexposed healthy control group $(n=84)$ which was statistically significant for IL4 $(p=0.004)$. In this study the level of dioxin exposure was evaluated by measuring the aerial dioxin concentrations in the working area of the company that was 100 times higher than that of the control population. In a study among company workers involved in 


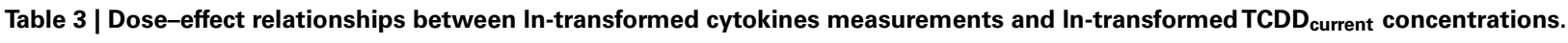

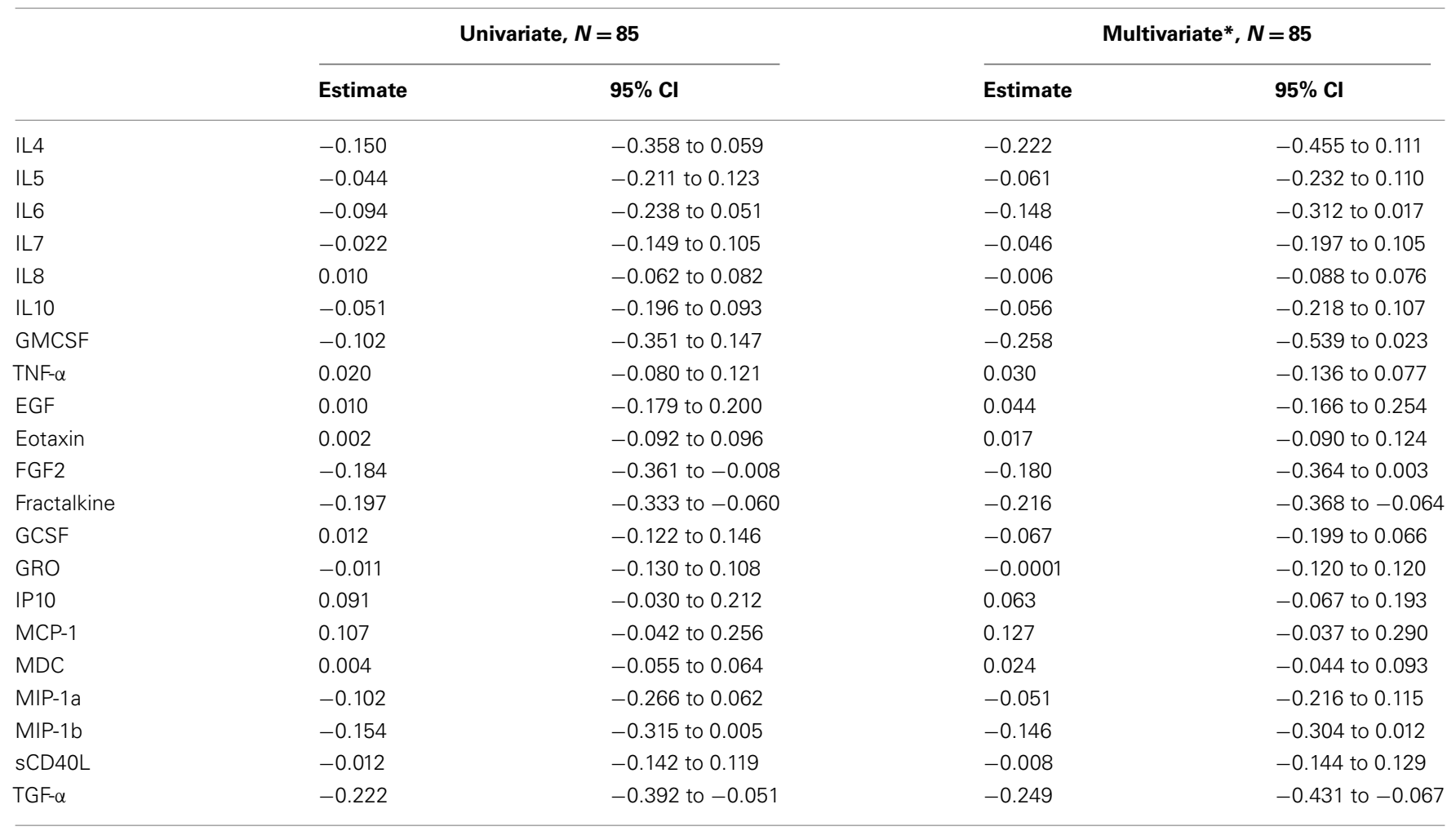

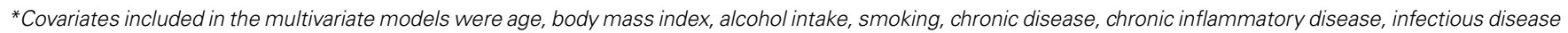
within 4 weeks before blood sampling, medication, and test day/batch.

decontamination work, Neubert et al. (2000) reported no changes in plasma levels of IL1 $\alpha$, IL1 $\beta$, IL6, and TNF- $\alpha$ among TCDD exposed subjects $(n=12$, TCDD level $=23-140 \mathrm{ppt})$ compared to low-exposed $(n=33$, TCDD level $=1-3 \mathrm{ppt})$ and medium exposed subjects $(n=28$, TCDD level $=4-9 \mathrm{ppt})$ despite a general reduction in the median plasma levels of most measured analytes among the high-exposed group. Similar to these studies on blood cytokines we found a decrease in most analytes among which IL4, IL6, and TNF- $\alpha$, albeit non-significant. Immune suppression characterized by suppressed humoral and cell-mediated immunity is a well-known toxic endpoint of TCDD exposure in animal and experimental studies (Marshall and Kerkvliet, 2010). It is accepted that the toxic effects of TCDD generally are mediated through the aryl hydrocarbon receptor (AhR) signaling pathway (Marshall and Kerkvliet, 2010). However, the mechanistic pathways are unclear in humans. In a study on the relation between immune blood cells and TCDD levels among the same study population as presented here (Saberi Hosnijeh et al., submitted), we found an overall reduction in most blood cell counts in particular B lymphocyte cells. When we corrected the observed associations of the present study for white blood cells, monocytes, lymphocytes, and B lymphocyte cell counts results did not change for fractalkine, TGF- $\alpha$ and FGF2, and the other analytes with the exception of IL4, IL6, and GMCSF for which the association with TCDD became borderline statistically significant. Therefore, it seems that the general suppression observed for the measured analytes are independent of the observed reduction in cell counts among exposed subjects and that TCDD exposure in humans might therefore influence on both function and the number of immune cells.

We found a significant negative association between plasma levels of fractalkine and TCDD levels. Fractalkine is an atypical chemokine existing as membrane-bound and in soluble form. The soluble form of fractalkine is chemotactic to cytotoxic $\mathrm{T}$ cells and monocytes and natural killer cells (Imai et al., 1997; Raychaudhuri et al., 2001). It is likely that fractalkine might induce an antitumor immune response by recruiting these cells into tumor tissues and stimulating their adhesion to tumor cells. Moreover, the results of a study by Shiraishi et al. showed that the fractalkine gene is a direct target of the tumor suppressor p53. They have suggested that p53 may eliminate aberrant/damaged cells by the host immune response system through transcriptional regulation of fractalkine (Shiraishi et al., 2000). However, to date, there is no published literature on fractalkine levels in relation to TCDD exposure. Our finding for fractalkine is interesting as it has been shown that a decrease in fractalkine receptor (CX3CR1) expression might play a role in immune responses against adult $\mathrm{T}$ cell lymphoma (Shimizu et al., 2007).

Cell growth and differentiation are regulated by numerous growth factors and cytokines. There is growing animal and in vitro evidence that TCDD influences growth factor-dependent cellular pathways (Haarmann-Stemmann et al., 2009). It has been shown 


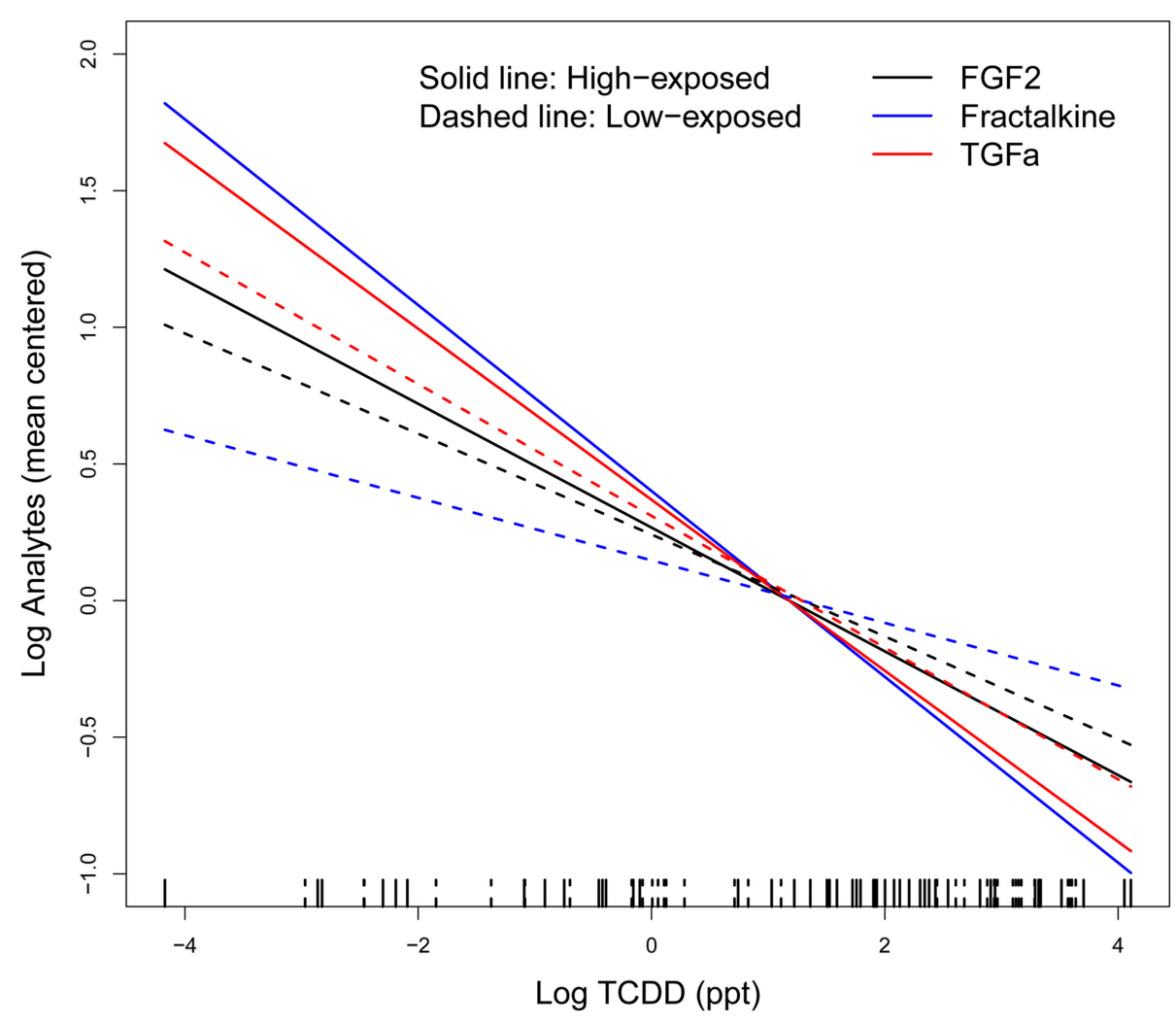

FIGURE 1 | Linear regression between In-transformed TCDD levels and In-transformed analytes (i.e., FGF2, Fractalkine, and TGF- $\alpha$ ) adjusted for age, body mass index, alcohol intake, smoking, chronic disease, chronic inflammatory disease, infectious disease within 4 weeks before blood sampling, medication, and test day/batch; solid line indicates high-exposed subjects and dashed line, low-exposed subjects on the rug plot. A group mean centering parameterization (group's mean is subtracted from the corresponding individual values) for the models was used to have equivalent models with identical deviance and residual errors; TCDD exposure levels between high- and low-exposed workers largely overlap. that inhibited expression of some growth factors including EGF, TGF- $\alpha$, and TGF- $\beta$ levels are main influencing factors during TCDD-induced developmental effects in animals (Abbott et al., 2003; Puga et al., 2005). A recent animal study on prostatic budding impairment after TCDD exposure suggested that TCDD likely acts through downstream of FGFR2 and extracellular signal-regulated kinase (Vezina et al., 2010). In vitro human studies showed that TCDD exposure induced post-transcriptional TGF- $\alpha$ expression in culture of human keratinocyte cell line (Choi et al., 1991; Gaido et al., 1992). Although TGF- $\alpha$ is expressed by epithelial cells, keratinocytes, and macrophages (Rappolee et al., 1988; Humphreys and Hennighausen, 2000), it is not clear whether other cell types can also produce TGF- $\alpha$ in response to TCDD exposure. Although we observed a statistical significant decrease in plasma levels of TGF- $\alpha$ and FGF2, the clinical significance of the results is not clear.

There are some limitations to our study including limited sample size, possible bias due to selective survival, and multiple testing. Moreover, residual confounding by smoking (no information on intensity and duration of smoking) is unlikely as smoking in general did not change the results. We had only a cross-sectional blood sampling that limited us in obtaining more insight into acute vs. long-term changes in cytokines, chemokines, and growth factors levels. Finally, as in our study $\mathrm{TCDD}_{\max }$ and $\mathrm{TCDD}_{\text {current }}$ are highly correlated (Pearson correlation coefficient $0.97, p<0.01$ ), it was difficult to differentiate between effects that might be related to high levels of exposure in the past $\left(\mathrm{TCDD}_{\max }\right)$ and effects related to current TCDD levels.

In conclusions, our results showed that plasma levels of TCDD were associated with an overall decrease in blood levels of most cytokines, chemokines, and growth factors which were statistically significant for fractalkine, FGF2, and TGF- $\alpha$. These results provide evidence of immunological effects of TCDD in humans and provide additional support for lymphomagenesis of TCDD.

\section{ACKNOWLEDGMENTS}

We would like to thank Wayman E Turner for blood plasma analyses of PCDDs, PCDFs, and PCBs (Division of Environmental Health Laboratory Sciences, Centers for Disease Control and Prevention, Atlanta, GA, USA). Furthermore, we gratefully acknowledge Nena Burger for cytokine analyses (Institute for Risk Assessment Sciences, Utrecht University, The Netherlands). We wish to thank all workers for participation in the study. The first author also acknowledges the Iranian Ministry of Health and Medical Education and IRAS foundation for supporting a Ph.D. program at Utrecht University in the Netherlands. 


\section{REFERENCES}

Abbott, B. D., Lin, T., Rasmussen, N. T., Albrecht, R. M., Schmid, J. E., and Peterson, R. E. (2003). Lack of expression of EGF and TGF- $\alpha$ in the fetal mouse alters formation of prostatic epithelial buds and influences the response to TCDD. Toxicol. Sci. 76, 427-436.

Bertazzi, P. A., Consonni, D., Bachetti, S., Rubagotti, M., Baccarelli, A., Zocchetti, C., and Pesatori, A. C. (2001). Health effects of dioxin exposure: a 20-Year Mortality Study. Am. J. Epidemiol. 153, 1031-1044.

Bodner, K. M., Collins, J. J., Bloemen, L. J., and Carson, M. L. (2003). Cancer risk for chemical workers exposed to 2,3,7,8-tetrachlorodibenzo-pdioxin. Occup. Environ. Med. 60, 672-675.

Boers, D., Portengen, L., Bueno-deMesquita, H. B., Heederik, D. J. J., and Vermeulen, R. (2010). Cause-specific mortality of Dutch chlorophenoxy herbicide manufacturing workers. Occup. Environ. Med. 67, 24-31.

Boers, D., Portengen, L., Turner, W. E., Bueno-de-Mesquita, H. B., Heederik, D., and Vermeulen, R. (2012). Plasma dioxin levels and cause-specific mortality in an occupational cohort of workers exposed to chlorophenoxy herbicides, chlorophenols and contaminants. Occup. Environ. Med. 69, 113-118.

Boverhof, D. R., Tam, E., Harney, A. S., Crawford, R. B., Kaminski, N. E., and Zacharewski, T. R. (2004). 2,3,7,8-Tetrachlorodibenzop-dioxin induces suppressor of cytokine signaling 2 in murine B cells. Mol. Pharmacol. 66, 1662-1670.

Bueno de Mesquita, H. B., Doornbos, G., van der Kuip, D. A., Deirdre, A. M., Kogevinas, M., and Winkelmann, R. (1993). Occupational exposure to phenoxy herbicides and chlorophenols and cancer mortality in the Netherlands. Am. J. Ind. Med. 23, 289-300.

Choi, E. J., Toscano, D., Ryan, J., Riedel, N., and Toscano, W. (1991). Dioxin induces transforming growth factor-alpha in human keratinocytes. J. Biol. Chem. 266, 9591-9597.

Consonni, D., Pesatori, A. C., Zocchetti, C., Sindaco, R., D’Oro, L. C., Rubagotti, M., and Bertazzi, P. A. (2008). Mortality in a population exposed to dioxin after the Seveso, Italy, accident in 1976: 25 years of follow-up. Am. J. Epidemiol. 167, 847-858.
Dave, S. S. (2010). Host factors for risk and survival in lymphoma. Hematology 2010, 255-258.

Dean, M., Jacobson, L. P., McFarlane, G., Margolick, J. B., Jenkins, F. J., Howard, O. M., Dong, H. F., Goedert, J. J., Buchbinder, S., and Gomperts, E. (1999). Reduced risk of AIDS lymphoma in individuals heterozygous for the CCR5- $\$ 32$ mutation. Cancer Res. 59, 3561-3564.

Fujimaki, H., Nohara, K., Kobayashi, T., Suzuki, K., Eguchi-Kasai, K., Tsukumo, S., Kijima, M., and Tohyama, C. (2002). Effect of a single oral dose of 2,3,7,8tetrachlorodibenzo-p-dioxin on immune function in male NC/Nga mice. Toxicol. Sci. 66,117-124.

Gaido, K., Maness, S., Leonard, L., and Greenlee, W. (1992). 2, 3, 7, 8-Tetrachlorodibenzo-p-dioxindependent regulation of transforming growth factors-alpha and $\beta 2$ expression in a keratinocyte cell line involves both transcriptional and post-transcriptional control. J. Biol. Chem. 267, 24591-24595.

Gascoyne, R. D., and Steidl, C. (2011). The role of the microenvironment in lymphoid cancers. Ann. Oncol. 22, iv47-iv50.

Haarmann-Stemmann, T., Bothe, H., and Abel, J. (2009). Growth factors, cytokines and their receptors as downstream targets of aryl hydrocarbon receptor (AhR) signaling pathways. Biochem. Pharmacol. 77, 508-520.

Hardell, L., Lindström, G., van Bavel, B., Fredrikson, M., and Liljegren, G. (1998). Some aspects of the etiology of non-Hodgkin's lymphoma. Environ. Health Perspect. 106, 679-681.

Hooiveld, M., Heederik, D. J. J., Kogevinas, M., Boffetta, P., Needham, L. L., Patterson, D. G. Jr., and Buenode-Mesquita, H. B. (1998). Second follow-up of a Dutch cohort occupationally exposed to phenoxy herbicides, chlorophenols, and contaminants. Am. J. Epidemiol. 147, 891-899.

Humphreys, R. C., and Hennighausen, L. (2000). Transforming growth factor alpha and mouse models of human breast cancer. Oncogene 19, 1085-1091.

Imai, T., Hieshima, K., Haskell, C., Baba, M., Nagira, M., Nishimura, M., Kakizaki, M., Takagi, S., Nomiyama, H., Schall, T. J., and Yoshie, O. (1997). Identification and molecular characterization of fractalkine receptor CX3CR1, which mediates both leukocyte migration and adhesion. Cell 91, 521-530.
Ito, T., Inouye, K., Fujimaki, H., Tohyama, C., and Nohara, K. (2002). Mechanism of TCDD-induced suppression of antibody production: effect on $\mathrm{T}$ cell-derived cytokine production in the primary immune reaction of mice. Toxicol. Sci. 70, 46-54.

Kim, H. A., Ki, E. M., Park, Y. C., Yu, J. Y., Hong, S. K., Jeon, S. H., Park, K. L., Hur, S. J., and Heo, Y. (2003). Immunotoxicological effects of agent orange exposure to the Vietnam war Korean veterans. Ind. Health 41, 158-166.

Kogevinas, M., Becher, H., Benn, T. Bertazzi, P. A., Boffetta, P., Buenode-Mesquita, H. B., Coggon, D., Colin, D., Flesch-Janys, D., Fingerhut, M., Green, L., Kauppinen, T., Littorin, M., Lynge, E., Mathews, J. D., Neuberger, M., Pearce, N., and Saracci, R. (1997). Cancer mortality in workers exposed to phenoxy herbicides, chlorophenols, and dioxins an expanded and updated international cohort study. Am. J. Epidemiol. 145, 1061-1075.

Lubin, J. H., Colt, J. S., Camann, D., Davis, S., Cerhan, J. R., Severson, R. K., Bernstein, L., and Hartge, P. (2004). Epidemiologic evaluation of measurement data in the presence of detection limits. Environ. Health Perspect. 112, 1691-1696.

Marshall, N. B., and Kerkvliet, N. I. (2010). Dioxin and immune regulation. Ann. N. Y. Acad. Sci. 1183, 25-37.

Neubert, R., Maskow, L., Triebig, G., Broding, H. C., Jacob-Müller, U., Helge, H., and Neubert, D. (2000). Chlorinated dibenzo-pdioxins and dibenzofurans and the human immune system: 3 . Plasma immunoglobulins and cytokines of workers with quantified moderately-increased body burdens. Life Sci. 66, 2123-2142.

Nohara, K., Fujimaki, H., Tsukumo, S., Inouye, K., Sone, H., and Tohyama, C. (2002). Effects of 2,3,7,8-tetrachlorodibenzo-p-

dioxin (TCDD) on $\mathrm{T}$ cell-derived cytokine production in ovalbumin (OVA)-immunized $\mathrm{C} 57 \mathrm{Bl} / 6$ mice. Toxicology 172, 49-58.

Oh, E., Lee, E., Im, H., Kang, H., Jung, W., Won, N. H., Kim, E., and Sul, D. (2005). Evaluation of immunoand reproductive toxicities and association between immunotoxicological and genotoxicological parameters in waste incineration workers. Toxicology 210, 65-80.

Patterson, D. J., Isaacs, S., Alexander, L., Turner, W., Hampton, L., Bernert, J., and Needham, L. (1991).
Determination of specific polychlorinated dibenzo-p-dioxins and dibenzofurans in blood and adipose tissue by isotope dilution-highresolution mass spectrometry. IARC Sci. Publ. 108, 299-342.

Pillemer, S. R. (2006). Lymphoma and other malignancies in primary Sjögren's syndrome. Ann. Rheum. Dis. 65, 704-706.

Puga, A., Tomlinson, C. R., and Xia, Y. (2005). Ah receptor signals crosstalk with multiple developmental pathways. Biochem. Pharmacol. 69, 199-207.

Purdue, M. P., Lan, Q., Bagni, R., Hocking, W. G., Baris, D., Reding, D. J., and Rothman, N. (2011). Prediagnostic serum levels of cytokines and other immune markers and risk of non-Hodgkin lymphoma. Cancer Res. 71, 4898-4907.

Rappolee, D. A., Mark, D., Banda, M. J., and Werb, Z. (1988). Wound macrophages express TGF-alpha and other growth factors in vivo: analysis by mRNA phenotyping. $S c i$ ence 241, 708-712.

Raychaudhuri, S. P., Jiang, W., and Farber, E. M. (2001). Cellular localization of fractalkine at sites of inflammation: antigen-presenting cells in psoriasis express high levels of fractalkine. Br. J. Dermatol. 144, 1105-1113.

Rothman, N., Skibola, C. F., Wang, S. S., Morgan, G., Lan, Q., Smith, M. T., Spinelli, J. J., Willett, E., De Sanjose, S., Cocco, P., Berndt, S. I., Brennan, P., Brooks-Wilson, A., Wacholder, S. Becker, N., Hartge, P., Zheng, T., Roman, E., Holly, E. A., Boffetta, P., Armstrong, B., Cozen, W., Linet, M. Bosch, F. X., Ennas, M. G., Holford, T. R., Gallagher, R. P., Rollinson, S., Bracci, P. M., Cerhan, J. R., Whitby, D., Moore, P. S., Leaderer, B., Lai, A., Spink, C., Davis, S., Bosch, R., Scarpa, A., Zhang, Y., Severson, R. K., Yeager, M., Chanock, S., and Nieters, A. (2006). Genetic variation in TNF and IL10 and risk of non-Hodgkin lymphoma: a report from the InterLymph Consortium. Lancet Oncol. 7 , 27-38.

Saberi Hosnijeh, F., Boers, D., Portengen, L., Bueno-de-Mesquita, H. B., Heederik, D., and Vermeulen, R. (2011). Long-term effects on humoral immunity among workers exposed to $2,3,7,8$ tetrachlorodibenzo-p-dioxin (TCDD). Occup. Environ. Med. 68, 419-424.

Shimizu, K., Karube, K., Arakawa, F., Nomura, Y., Komatani, H., Yamamoto, K., Yoshida, S., Aoki, R., Sugita, Y., and Takeshita, M. (2007). 
Upregulation of CC chemokine ligand 18 and downregulation of CX3C chemokine receptor 1 expression in human T-cell leukemia virus type 1-associated lymph node lesions: results of chemokine and chemokine receptor DNA chip analysis. Cancer Sci. 98, 1875-1880.

Shiraishi, K., Fukuda, S., Mori, T., Matsuda, K., Yamaguchi, T., Tanikawa, C., Ogawa, M., Nakamura, Y., and Arakawa, H. (2000). Identification of fractalkine, a CX3C-type chemokine, as a direct target of p53. Cancer Res. 60, 3722-3726.
Vezina, C. M., Hardin, H. A., Moore, R. W., Allgeier, S. H., and Peterson, R. E. (2010). 2,3,7,8-tetrachlorodibenzop-dioxin inhibits fibroblast growth factor 10-induced prostatic bud formation in mouse urogenital sinus. Toxicol. Sci. 113, 198-206.

Zhang, Q., Bhattacharya, S., Kline, D., Crawford, R., Conolly, R., Thomas, R., Kaminski, N., and Andersen, M. (2010). Stochastic modeling of B lymphocyte terminal differentiation and its suppression by dioxin. BMC Syst. Biol. 4, 40. doi:10.1186/1752-0509-4-40
Conflict of Interest Statement: The authors declare that the research was conducted in the absence of any commercial or financial relationships that could be construed as a potential conflict of interest.

Received: 22 December 2011; paper pending published: 01 March 2012; accepted: 27 March 2012; published online: 11 April 2012.

Citation: Saberi Hosnijeh F, Boers $D$, Portengen L, Bueno-de-Mesquita $H B$, Heederik $D$ and Vermeulen $R$ (2012) Plasma cytokine concentrations in workers exposed to 2,3,7,8-tetrachlorodibenzo-p-dioxin (TCDD). Front. Oncol. 2:37. doi: 10.3389/fonc.2012.00037

This article was submitted to Frontiers in Cancer Epidemiology and Prevention, a specialty of Frontiers in Oncology. Copyright () 2012 Saberi Hosnijeh, Boers, Portengen, Bueno-de-Mesquita, Heederik and Vermeulen. This is an openaccess article distributed under the terms of the Creative Commons Attribution Non Commercial License, which permits non-commercial use, distribution, and reproduction in other forums, provided the original authors and source are credited. 